\title{
EXPERIMENTAL DIABETES INSIPIDUS *
}

\author{
PERCIVAL BAILEY AND FRÉDÉRIC BREMER \\ BOSTON BRUSSELS \\ INTRODUCTION AND HISTORY
}

It has been known for a long time that tumors and other pathologic lesions in the region of the sella turcica are attended by far-reaching pathologic alterations in other parts of the body. For some time also it was a matter of dispute among clinicians as to whether the symptoms were due essentially to lesion of the pituitary gland or of the immediately adjacent base of the brain (Erdheim $\left.{ }^{1}\right)$. Recently this controversy has arisen anew in the contradictory articles of Leschke ${ }^{2}$ and Marañón. ${ }^{3}$

In 1907 Paulesco ${ }^{4}$ opened the way to a solution of the question by developing a method of operative approach to the region of the sella. By this method, perfected by Cushing and developed by him and his associates, operative procedures on the pituitary gland became relatively easy.

Cushing ${ }^{5}$ was the first to note, after experimental lesions of the pituitary in dogs, the development of a syndrome identical with that known clinically as adiposogenital dystrophy. The syndrome in his experience followed most frequently division of the pituitary stalk, an observation recently confirmed by Bell. ${ }^{6}$ The same dogs had a persistent polyuria. These results are usually attributed to deficiency of the secretion of the pituitary gland: the adiposogenital dystrophy to deficiency of the anterior lobe, the polyuria, to deficiency of the posterior lobe secretion. The latter opinion concerning the polyuria has been supported by the effects of subcutaneous injection of pituitrin and is widely accepted.

Shortly afterwards Aschner ${ }^{7}$ operating by the buccal route on dogs, denied the possibility of producing adiposity in adult animals by removal of the gland. On the other hand, he reported, after hypophysectomy in young dogs, the production of adiposity, genital aplasia, high

\footnotetext{
* From the Laboratory of Surgical Research, Harvard Medical School, and Surgical Clinic, Peter Bent Brigham Hospital.

1. Erdheim: Sitzungsb. d. k. Akad. d. Wissensch., math. naturw. Cl., Wien., Abt. 3 113:537, 1904.

2. Leschke: Ztschr. f. klin. Med. 87:201, 1919.

3. Marañón: Nuevas orientaciones sobre-de la Diabetes Insipida, 1920.

4. Paulesco: L'hypophyse du cerveau, 1907.

5. Cushing: The Pituitary Body, 1912.

6. Bell: The Pituitary, 1920.

7. Aschner: Arch. f. d. ges. Physiol. 146:1, 1912.
} 
adrenalin tolerance, and general underdevelopment, a syndrome identical with that known clinically as pituitary infantilism. These symptoms he ascribed to lack of the pituitary secretion. The occasional occurrence in adult animals of other symptoms noted by Cushing, such as cachexia, subnormal temperature, adiposity, genital atrophy and death, he thought to be due to gross lesion of the brain. This latter assumption was purely gratuitous as any one who has examined a brain after a temporal pituitary operation must realize, even when done by a much less skillful surgeon than Cushing.

Aschner was vigorously criticized by $\mathrm{Biedl}^{8}$ for assuming such a totally unknown hypothetical nervous center as a cause for the symptoms. And there is an evident lack of coordination in Aschner's conclusions in that he attributed the genital atrophy in young animals to lack of pituitary secretion and the identical condition in adult animals to a lesion of the base of the brain! Indeed, at that time so little was known concerning the connections and functions of the part of the brain just above the pituitary, that the idea that a lesion in this region so small as to escape naked-eye examination could cause such widespread results as polyuria, genital atrophy, adiposity, cachexia, and even death must have seemed to any one absurd. But though at the outset confusion and contradiction existed in the physiology of the pituitary, it came to be generally accepted that adiposogenital dystrophy and polyuria were due to an hypophysial lesion.

Since that time, however, some experiments have been reported, acute and rough though they were, which seem to indicate that in the base of the brain just over the pituitary is a very important center, intimately connected with the entire visceral nervous system. Lesion or stimulation of this region, known to anatomists as the hypothalamus, is said to be followed by dilatation of the pupil (Karplus and $\mathrm{Kreidl}^{9}$ ), a disturbance of heat regulation (Isenschmidt and Krehl, ${ }^{10}$ Ott, ${ }^{11}$ Leschke, ${ }^{2}$ Barbour ${ }^{12}$ ), glycosuria (Aschner ${ }^{13}$ ), polypnea (Garrelon and Langlois ${ }^{14}$ ) and many other symptoms.

The anatomic relations of the hypothalamus are still imperfectly understood, but it is known to be closely related to the olfactory and gustatory (Herrick ${ }^{15}$ ) systems, which are highly specialized parts of the visceral nervous system. There is also some evidence of

8. Biedl: Innere Sekretion, 1912.

9. Karplus and Kreidl: Arch. f. d. ges. Physiol. 129:138, 1909.

10. Isenschmidt and Krehl: Arch. f. exper. Path. u. Pharmakol. 70:109, 1913.

11. Ott: Fever, Its Thermotaxis and Metabolism, 1915.

12. Barbour: Physiological Reviews 1:295, 1921.

13. Aschner: Berl. klin. Wchnschr. 53:772, 1916.

14. Garrelon and Langlois: J. d. physiol. 15:566, 1913.

15. Herrick: J. Comp. Neurol. 15:375, 1905. 
its connection with the general visceral system (Brugsch, Dresel and Lewy ${ }^{10}$ ).

Camus and Roussy ${ }^{17}$ were the first to undertake to control systematically the physiology of the pituitary by puncturing the base of the brain. Already in 1913 they had reported to the Société de biologie that they were able to produce transitory polyuria by puncturing the hypothalamus of dogs through the sphenoid bone with a heated drill. In one $\operatorname{dog}$ a permanent polyuria and in addition adiposogenital dystrophy had resulted. However, no microscopic examination was reported and it was often evident on gross examination that a lesion of the pituitary also existed. Especially was this true in the more interesting of their dogs, the one with a permanent diabetes insipidus with testicular atrophy. The report stated that the lesion lay in front of the infundibulum. This was much dilated, and the pituitary itself weighed only $20 \mathrm{cg}$. They concluded that the polyuria was due to a lesion of the gray matter of the tuber cinereum in the region of the infundibulum. They were not affirmative about the adiposogenital syndrome.

From time to time since then they have reported further experiment, ${ }^{18}$ and have shown conclusively that the polyuria does not depend on a lesion of the hypophysis by producing it in a dog from which the hypophysis had been previously removed. The removal of the hypophysis was followed by a transitory polyuria. More than a month later, after the polyuria had subsided, a second polyuria of equal intensity was produced by puncture of the tuber cinereum. Their conclusions have been supported by Houssay ${ }^{19}$ without adding any new information. It is interesting, in view of the results given later in this paper, that he was unable to produce these symptoms in operating by the temporal route, probably because of unfamiliarity with the - operative procedure.

Recently Camus and Roussy ${ }^{20}$ in demonstrating two dogs with adiposogenital dystrophy to the Société de neurologie admitted that a lesion of the pituitary was probably present, although they brought strong arguments to show that it was not essential. Indeed in operating by their method it is difficult to avoid puncturing the pituitary, which lies directly under the hypothalamus.

Since it seemed difficult to arrive at a decision by this method with its almost necessary concomitant injury of the hypophysis, we 1920.

16. Brugsch, Dresel and Lewy: Ztschr. f. exper. Path. u. Therap. 21:358,

17. Camus and Roussy: Compt. rend. soc. Biol. 75:483, 1913.

18. Camus and Roussy: Endocrinology 4:507, 1920; Compt. rend. soc. Biol. T. $83: 1578,1920$.

19. Houssay: Endocrinology 2:94, 1918; Compt. rend. soc. Biol. 81:381, 1918.

20. Camus and Roussy: Rev. neurol. 27:1113, 1920. 
determined to attack the hypothalamus by the temporal route, which allows an exposure of the entire region, with intent to study in detail the resulting polyuria. The lesion can be produced where desired, and the pituitary, being in plain view, carefully avoided. Needless to say, no trauma whatsoever is produced by the slight cerebral dislocation necessary for this exposure.

The present report is concerned with a series of such experiments, with especial reference to the resulting polyuria, leaving the discussion of the adiposogenital syndrome for a later communication.

\section{METHODS}

Dogs were used throughout our experiments. The technic of the temporal operation has been described in detail by Crowe, Cushing and Homans. ${ }^{21}$ After the first few operations this procedure was modified somewhat to suit our purposes. The curved incision used by Bell ${ }^{6}$ was found adequate. On the right side a subtemporal decompression was done as usual. On the left side we adopted practically the procedure of Sweet and Allen. ${ }^{22}$

The superficial muscles are drawn down below the zygoma. A horizontal incision is then made through the periosteum along the middle of the zygoma for its entire length. The periosteum is stripped off the zygoma upward and downward. The zygoma is resected. From the middle of this horizontal incision another is made through the temporal muscle slanting upward and backward in the direction of the muscle fibers. In the upper part this latter incision is carried down to the skull. In the lower part the coronoid process of the mandible intervenes and must be removed before the incision can be extended downward. The temporal muscle is stripped from the skull and held to right and left with retractors. The bone is then trephined and the operation continued as usual. This procedure permits of a very low approach, direct access to the pituitary with a minimum of retraction of the brain and a perfect closure.

The pituitary region having been brought into view it is easy to recognize optic nerves, stalk, pituitary, internal carotid, etc., and to make lesions in any part of the hypothalamus at will. For making the lesion in the brain at first we used a right-angled knife which was slid between the pituitary and base of the brain, the point turned upward, thrust into the brain and then drawn to one side. After cutting the circle of Willis, however (Dog 12), it was discarded for a sharp right-angled probe. After the first three dogs also we contented ourselves with a much smaller lesion.

A few buccal operations were done following the technic described by Aschner, ${ }^{7}$ and also a few punctures after the manner of Camus and Roussy by boring through the sphenoid with a dental drill, and puncturing the brain with a sharp probe.

The brains were removed as described by Crowe, Cushing and Homans after fixation in situ by carotid injection of formalin, with

21. Crowe, Cushing and Homans: Johns Hopkins Hosp. Bull. 21:127, 1910.

22. Sweet and Allen: Ann. Surg. 57:485, 1913. 
the exception of Nos. 10, 17 and 22. In these cases the body of the sphenoid was removed through the mouth as in a buccal operation and the dura carefully cut around the edge of the bony defect. The brains were then removed as before from above, the dura remaining attached to the entire hypothalamic region.

The hypothalamus was removed in one block, from the optic chiasm to the pons, with the pituitary attached. The block was embedded in celloidin, cut in 20 microns serial sections, and stained with van Giesen's mixture. In Dogs 7, 13, 15 and 16 the pituitaries were cleanly severed from the brain, embedded in paraffin and cut 6 microns in series for more careful study since in these cases there was some question of injury to the pituitary. In Dog 10 , every fourth section of the brain was stained with thionin.

\section{PROTOCOLS}

The location of the lesion in each dog except the first two may be seen by referring to Plate 1.

Dogs 1 AND 2.-Aduit dogs: No. 1, partial anterior lobe removal, verified histologically. No. 2, posterior lobe removal, verified histologically. Neither dog had polyuria. At necropsy the remaining pituitary tissue normal histologically in each case. Base of brain not sectioned.

Dog 3.-Male, adult, $13.2 \mathrm{~kg}$. Puncture by temporal procedure, November 3; previous average output 300 c.c. Polyuria second day. Maximum 1,500 c.c., November 12. Apathy, drowsiness, arched back, convulsions, hypothermia. Died in convulsion November 15.

Necropsy.-General examination negative; microscopically, lesion a puncture wound of the hypothalamus extending upward and forward to a depth of about $3 \mathrm{~mm}$. Lesion directly back of the stalk of the hypophysis and slightly to the right of the midline. Hypophysis microscopically and macroscopically normal. Meninges normal. Testis showed acute atrophy of spermatogenic elements; rarely a spermatozoa or a spermatid is seen and they are absent in many tulbules where the wall is composed of Sertoli cells and a few scattered spermatogonia; the spermatocytes show signs of degeneration in form of increased fat content. Suprarenal, pancreas, liver and kidney histologically normal.

Dog 4.-Male, adult, $25 \mathrm{~kg}$. Temporal puncture November 18; previous average output 500 c.c. Polyuria the same day, 1,030 c.c. Coma, convulsions, death on the third day.

Necropsy.-Subcutaneous infection on left side. Meninges normal. General findings negative. Clean knife cut transversely across hypothalamus just back of stalk of hypophysis extending upward to a depth of $4 \mathrm{~mm}$. Hypoph$y$ sis intact. No signs of infection of the meninges.

DoG 5.-Male, adult, $11.8 \mathrm{~kg}$. Temporal puncture November 30. Previous average output 700 c.c. Glycosuria first day. Polyuria the third day. Maximum 1.200 c.c. on sixth day. Apathy, drowsiness, arched back. Polyuria ceased the ninth day. Killed December 21.

Necropsy.-General findings negative. Microscopically two knife cuts, one into the mamillary bodies, the other just back of them extending upward about $3 \mathrm{~mm}$. Hypophysis intact.

Dog 6.-Male, adult, $12 \mathrm{~kg}$. Temporal puncture December 2. Previous average output 450 c.c. Polyuria the second day. Maximum 1,500 c.c. the third day. Polyuria ceased the seventh day. Aschner buccal operation, 
December 18. Puncture in front of hypophysis. No polyuria, no symptoms except left hemianopsia. Killed January 31 .

Necropsy.-General findings negative. Meninges normal. Two lesions, one a small puncture wound just behind and to the right of the hypophysis and extending to a depth of about $2 \mathrm{~mm}$., the other a much deeper one extending from the optic chiasm to the thalamus. Pituitary intact.

Dog 7.-Male, puppy, 8 months, $13.4 \mathrm{~kg}$. Average output 200 c.c. Aschner buccal operation March 1. Dura not opened. Curved dental probe slid around hypophysis and thrust into brain above it. No bleeding. Marked polypnea. Polyuria the first day 960 c.c., apparent recovery. Died the third day of meningitis.

Necropsy.-Meningitis. Puncture wound extending through the left mamillary body into midbrain. Pituitary infected.

Dog 9.-Male, adult, $15 \mathrm{~kg}$. Temporal puncture, January 18. Previous average output 350 c.c. Polyuria the second day. Maximum the third day, 1,160 c.c. Ceased the fifth day. Killed February 2.

Necropsy.-General findings negative. Superficial lesion just back and to the right of the stalk. Hypophysis intact (Plate 2).

Dog 10.-Male, adult, $12.9 \mathrm{~kg}$. Average output 450 c.c. Temporal puncture January 7. Enormous thirst. Polyuria the first day. Maximum the fifth day, 3,800 c.c. Permanent diabetes insipidus. Arched back and apathy the first days. Insidious and progressive drowsiness, obesity and genital atrophy. Kidneys denervated April 16. Transitory increase of polyuria and persistence later of the diabetes. Intramuscular injection of 4 c.c. epinephrin May 10, 9 a. m. No glycosuria. Killed May 10 in evening. Weight $20 \mathrm{~kg}$.

Necropsy.-Enormous accumulation of fat generalized. Atrophy of external genitalia and testes. Thyroid not enlarged. Meninges normal. V-shaped lesion in hypothalamus just back of the stalk of the hypophysis. The posterior limb extended upward through the anterior margin of the mamillary bodies; the anterior slanted forward over the stalk to a depth of $3 \mathrm{~mm}$. Anterior to the incision the cells of the tuber show chromatolytic changes. Behind the incision the nerve cells are normal. The entire pituitary was present. The posterior lobe had been detached from the infundibulum but was normal and its blood supply intact. The entire anterior lobe was present, its cells stained normally and its blood supply intact. Testes show an extensive atrophy of the spermatogenic elements. The spermatozoa are absent as well as most of the spermatids. Many pyknoses are seen in the spermatogonia. There is slight sclerosis of the walls of the tubules, very slight interstitial sclerosis, marked sclerosis of the albuginea, and extreme vascular sclerosis without endarteritis (Plate 3). The cells of the interstitial gland contain an abnormally large amount of fat which is collected in large globules. Suprarenal normal, lipoid content of cortex unaltered. Thyroid, parathyroid, pancreas, liver and kidney histologically normal.

Dog 12.-Male, adult, $12 \mathrm{~kg}$. Temporal operation January 25. Operation abandoned without puncture because of profuse hemorrhage from circle of Willis. No polyuria, Marked sleepiness, contrasting with an excellent general state and which persisted until the animal was sacrificed. No choked disk. Killed February 15. Extensive pachymeningitis hemorrhagica interna.

Dog 13.-Male, adult, $13.4 \mathrm{~kg}$. Average output 300 c.c. Temporal operation, February 7 , abandoned because of hemorrhage from cavernous sinus. No symptoms. Removal of hypophysis by Aschner buccal procedure, February 21. Polyuria the first day, 1,000 c.c. Died February 23, with temperature of $109 \mathrm{~F}$.

Necropsy. - General findings negative. Very little blood in subarachnoid space. No signs of infection. Pituitary entirely gone. Extensive lesion of the tuber cinereum which was not entirely destroyed but showed contusion and hemorrhage to a depth of $4 \mathrm{~mm}$. 

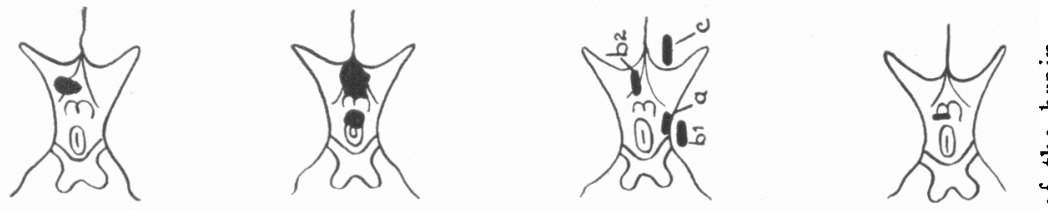

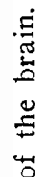

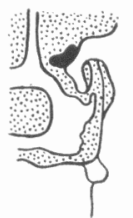

N
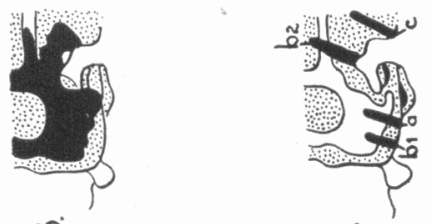

$\underline{\infty}$

i

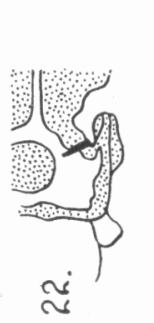

苈

$\stackrel{ \pm}{5}$

웅
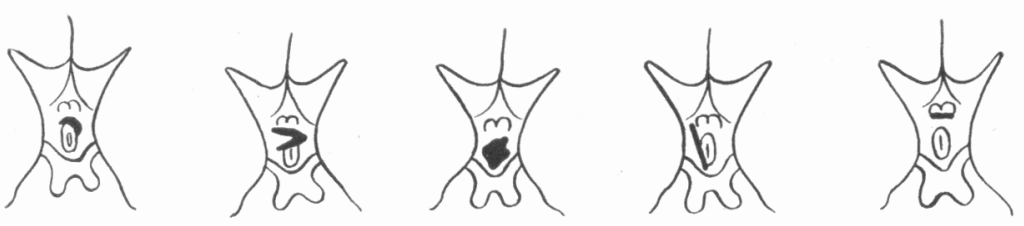

草

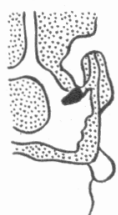

बi

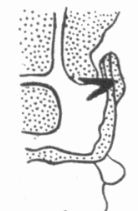

0

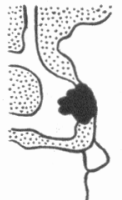

m
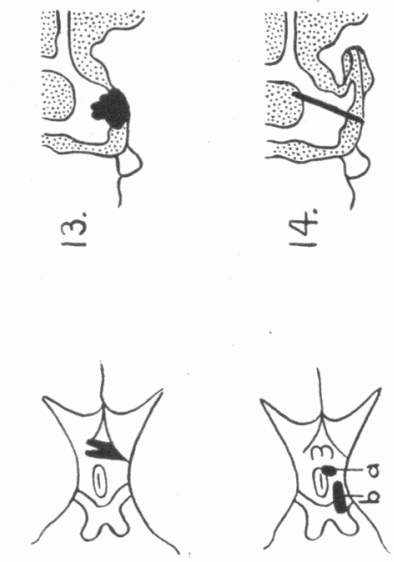

d
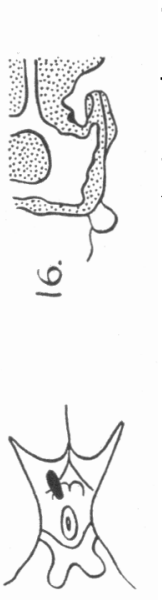
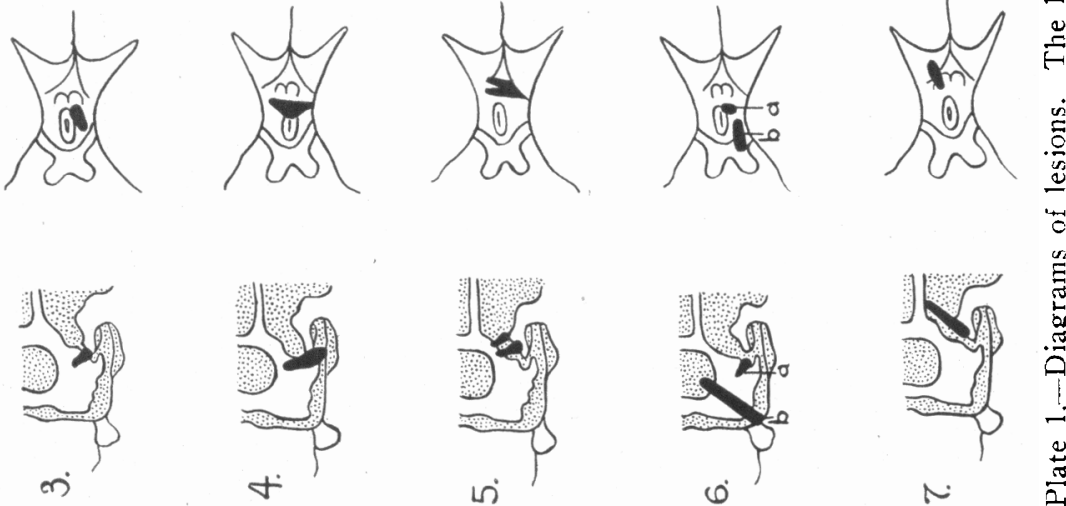

5

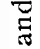

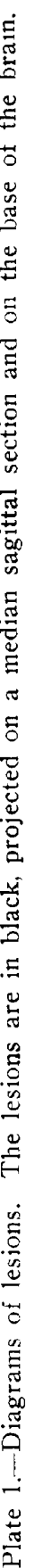


Dog 14.-Male, adu.t, $19.6 \mathrm{~kg}$. Chronic nephritis. Irregular polyuria, average 800 .c.c. Puncture through sphenoid with a dental drill. Immediate polypnea which lasted twenty-four hours. Polyuria the third day. Maximum 2.300 c.c. Ceased the seventh day. Traces of glucose the third day. Killed April 11.

Necropsy-CSmall contracted kidneys with capsule adherent. Minute puncture wound directly in front of the stalk of the hypophysis extending upward and backward to a depth of $15 \mathrm{~mm}$. (Plate 2). Hypophysis intact. Kidney showed subacute nephritis.

Dog 15.-Male, adult, $10.7 \mathrm{~kg}$. Temporal operation February 19. Strong trace of glucose first day. No polyuria. No other symptoms. Killed March 11.

Necropsy.-General findings negative. No lesion of hypothalamus could be found. Hypophysis intact.

Dog 16.-Male, adult, $13.6 \mathrm{~kg}$. Average output 400 c.c. Temporal operation, February 26. Strong trace of glucose the first day. Polyuria the second day. Maximum 1,700 c.c. on same day. Ceased the eighth day. Killed March 15.

Necropsy.-General findings negative. Meninges normal. Superficial lesion at anterior border of mamillary bodies. Hypophysis intact.

Dog 17.-Male, adult, $10 \mathrm{~kg}$. Temporal puncture March 29. Immediate polypnea. No polyuria. Died the first day.

Necropsy. - Considerable contusion of left temporal lobe. Lesion in left cerebral peduncle. Hypophysis intact.

Dog 18.-Female, adult, $10 \mathrm{~kg}$. Temporal operation, April 5. Slight polyuria. Strong glycosuria. Died April 6 in coma.

Necropsy.-Intraventricular hemorrhage.

Dog 21.-Male, adu!t. $12 \mathrm{~kg}$. Transsphenoidal puncture (a, Plate 1) April 23. No polyuria. Marked glycosuria. April 26, two similar punctures (b, b., Plate 1). Murked polypnea. No polyuria. Slight glycosuria. May 4, one similar puncture further back (c, Plate 1). No polyuria. Marked glycosuria. Killed May 10.

Necropsy.-Meninges normal. Four puncture wounds of the brain were found, only one of which (a) struck the optopeduncular region and was far lateral to the midline. One of the other three punctures struck the hypophysis producing a hemorrhage into the interlobar cleft.

Dog 22.-Male, young adult, $10 \mathrm{~kg}$. Average output $400 \mathrm{c.c}$. Temporal puncture April 29. Polyuria the second day which did not subside, maintaining an average of 1,100 c.c. Kidneys denervated May 15 , weight $15.2 \mathrm{~kg}$. Subcutaneous infection, very ill. When the infection subsided the polyuria reappeared. May 25 , weight $11 \mathrm{~kg}$., general condition improving rapidly. June 5 injection of 4 c.c. epinephrin intramuscularly. No glycosuria. Killed June 10, weight $13.2 \mathrm{~kg}$.

Necropsy-Moderate generalized deposit of fat. Evidence of previous extensive intramuscular infection of lumbar region. Meninges normal. Lesion in hypothalamus at anterior border of the mamillary bodies. Hypophysis intact. Testis showed acute atrophy; spermatozoa almost completely absent. spermatids absent in many tubules, the remaining ones with increased fat content, swollen and degenerating. Increased amount of fat in the interstitial cells also. Kidney, suprarenal, thyroid, pancreas and parathyroid histologically normal.

Dog 23.-Female, adult, weight $14.6 \mathrm{~kg}$. Average output 450 c.c., sp. gr. 1.026 . June 1, kidneys denervated. Polyuria reaching a maximum of 900 c.c. June 3, output 760 c.c. June 4 , temporal puncture, intake 1.800 c.c., output 600 c.c. June 5, apathetic. June 6, still apathetic; intake, 1,525 c.c., output, 997 c.c. June 7 , cachectic, apathetic, with head drooping, arched back, profuse thick salivation, slow pulse and repeated typical epileptic attacks. June 8, some- 


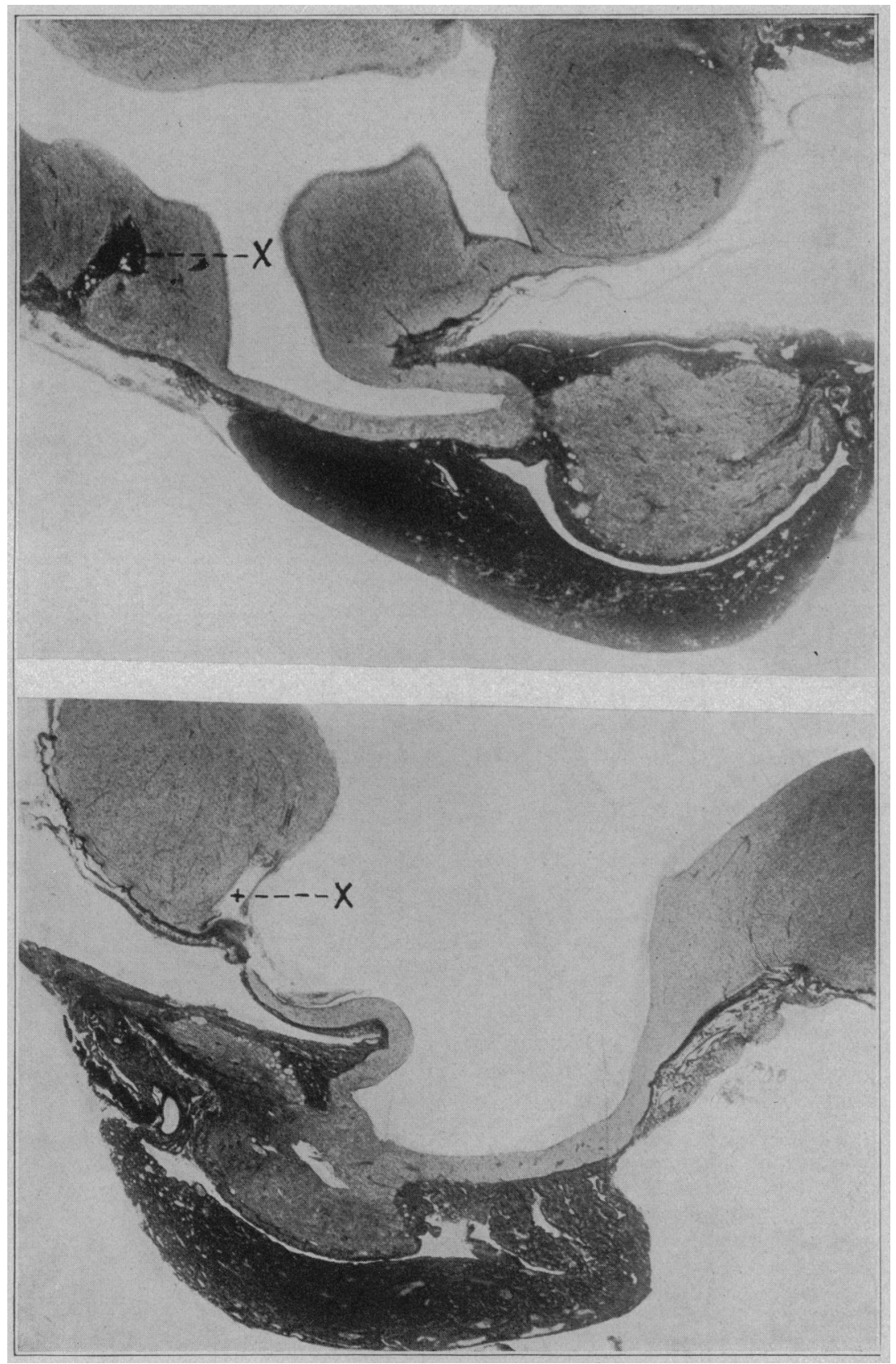

Plate 2.-Photomicrographs of approximately median sagittal sections of hypophysis and hypothalamus, $\times 14$. The sections are reversed. Lesions shown at $X$. Dog 14 above; $\operatorname{Dog} 9$ below. 
what improved, fewer attacks. June 10, much improved, injection of 4 c.c. epinephrin intramuscularly gave no glycosuria. June 11 , much improved, intake 800 c.c.. output 850 c.c., sp. gr. 1.018. Found dead in the morning of June 20.

\section{STUDY OF THE SYMPTOMS}

As an immediate result of the puncture we noted a sudden change in the respiratory rate which in one dog became a true polypnea lasting for twenty-four hours without other symptoms. In two cases also the animal gave a peculiar cry at the moment of puncture, both being nevertheless deeply narcotized at the time. We never observed any change in the rectal temperature within the first four hours.

1. The Glycosuria.-This was noted in six cases and had the characteristics of Claude Bernard's puncture glycosuria, the exact mechanism of which is still unknown. Stewart and Rogoff, ${ }^{23}$ confirming others, have shown recently that it may be produced as well in animals whose adrenals have been removed. We made no attempt to determine the exact mechanism of its production in our animals.

In four of these dogs there was also a polyuria and it is interesting to note that in $\operatorname{Dog} 14$, who had a chronic nephritis with marked retention of urea (nonprotein nitrogen 100), the trace of glucose appeared only on the third day along with the polyuria. It may be seen from the sketches (Plate 1, 5, 14, 16, 18) that in each case the hypothalamus was involved in some way.

Two dogs (15 and 21) had glycosuria without polyuria. Dog 21 was punctured three times by the buccal route and each time had glycosuria. The lesions in this animal were all in the outskirts of the hypothalamic region and in Dog 15 no lesion could be found. It seems that the glycosuria does not depend upon so localized a region as the polyuria, and its production is known to depend very greatly on the nutritional state of the animal.

2. Hyperthermia.-One dog (No. 13) following ablation of the pituitary by the buccal route, had a temperature of $109 \mathrm{~F}$. the second lay, and died. The lesion in this dog who had also polyuria but no glycosuria affected extensively the tuber cinereum.

It has been shown by Ott, Isenschmidt and Krehl and others that the hypothalamus is the most important thermic center in mammals: thermic regulation and the possibility of inducing fever is abolished after section of the brain stem just behind it. Puncture of this region is followed in the rabbit (Ott ${ }^{11}$ ) by an immediate and extreme hyperthermia. The same hyperthermia, usually fatal, may follow operations on the pituitary region in man. That we did not observe it more frequently in our experiments is probably due to the small size of the lesion.

23. Stewart and Rogoff: Am. J. Physiol. 46:90, 1918. 


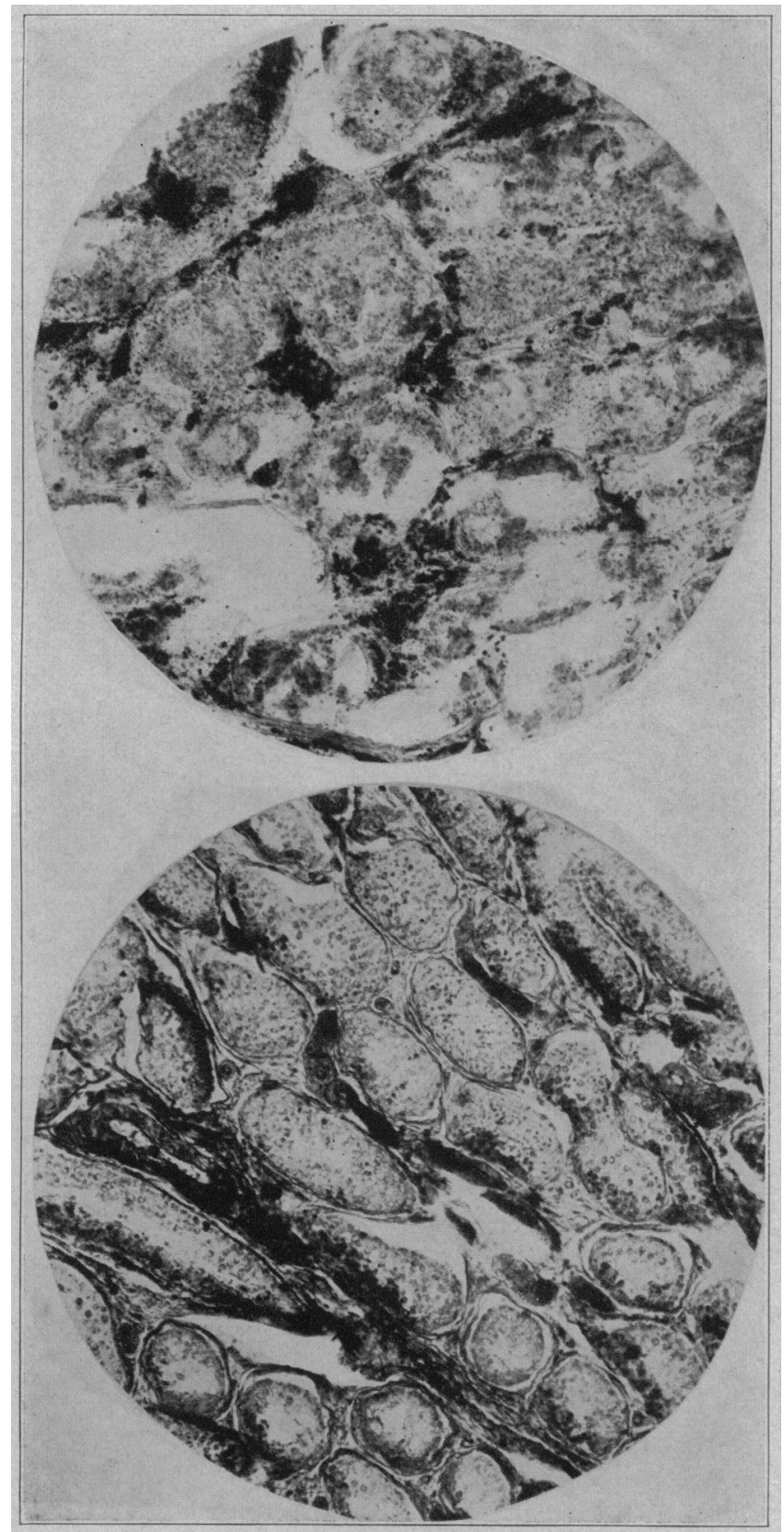

Plate 3.-Photomicrographs of sections from the testis of Dog $10 . \times 7()$. The upper is stained with scarlet red; the lower with hematoxylin and eosin. 
3. Polyuria.-In order to study the polyuria the dogs, kept in metabolism cages, were given free water supply and daily $11 / 2$ pounds of carefully weighed lean meat. The intake of water, output of urine, and the freezing point $(\Delta)$, specific gravity and total chlorids of the urine were charted. The presence of glucose and acetone in the urine was tested for before and after operation.

The daily output of urine on this regime in these animals, all adult, middle-sized dogs, varied from 200 to 500 c.c., but was very regular for each dog. Much more constant than the output were the freezing point and specific gravity. The freezing point varied between -3 and -4 in the different dogs, but each dog had a characteristic

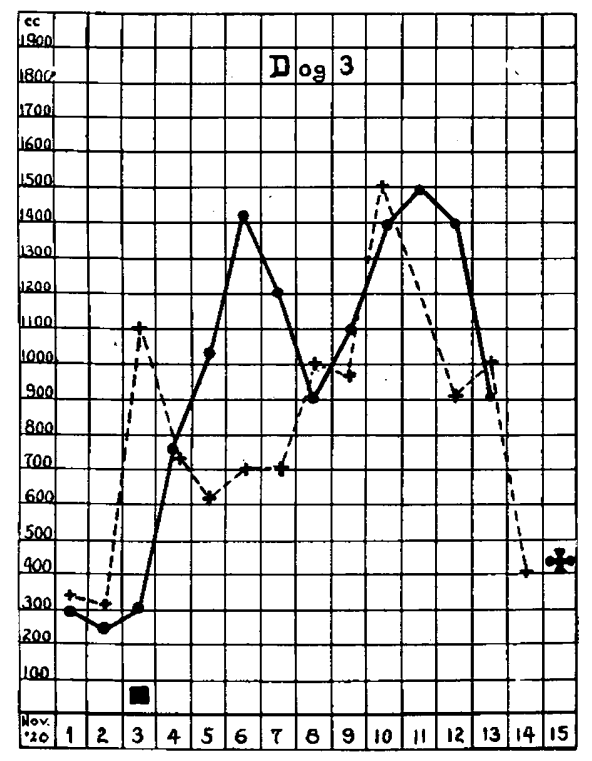

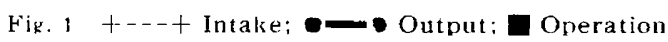

freezing point of an amazing constancy, fluctuating only two or three tenths of a degree. This is due to the fact that the dog eliminates urea to the maximal concentration (Ambard). After a few days of this regime poor in chlorids, the $\operatorname{dog}$ eliminates a minimal quantity of chlorids, from 0.8 to $1 \mathrm{gm}$., in twenty-four hours. They consist partially of potassium chlorid but for the sake of simplicity are evaluated in sodium chlorid. As has already been said, the dogs recovered completely within two hours after the operation. Most of them drank the day of operation and all, except the comatose ones and those operated by the buccal route, ate their entire ration the following day. Twelve of the fifteen punctured dogs had a polyuria.

Three dogs which were punctured had no polyuria (Nos. 15, 17 and 21). In Dog 15 no lesion could be found; in Dog 17 the only 
lesion was in the midbrain and in Dog 21 the lesions were all around the edge of the optopeduncular region. Besides Dog 12, submitted to the same operation but not punctured because of a profuse hemorrhage from the circle of Willis, had no polyuria.

The polyuria began for five dogs the first day, for six the second day and for one the third day. This last dog had a chronic nephritis with retention. Though there was apparently long latency of the effect of the puncture on the regulation of water, in three cases where the polyuria did not appear until the second day there was already on the first day a considerable increase in the intake of water as compared

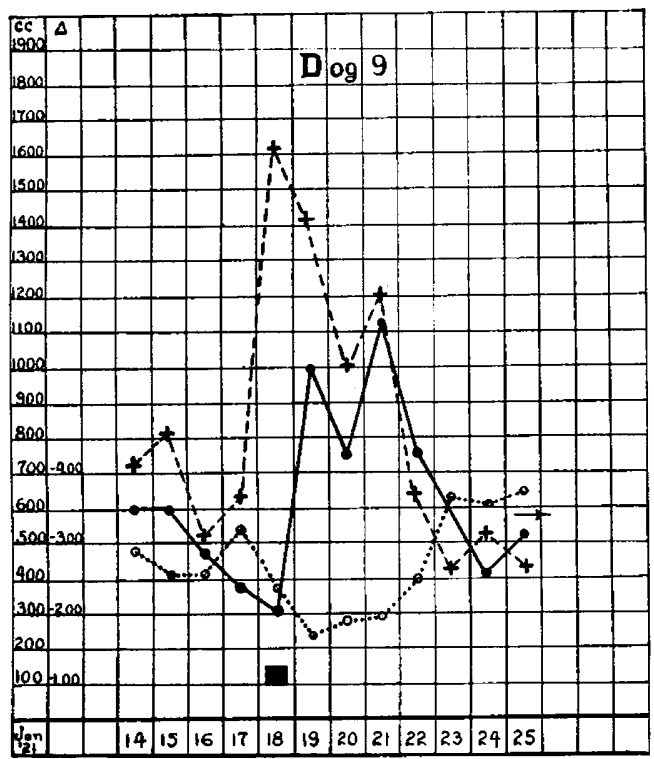

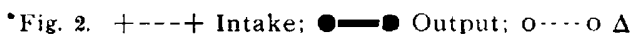

Operation.

with the preceding days (Fig. 1, 2 and 3). Furthermore, e. g. in Dog 10, there was great disproportion between the intake and output on the days immediately following the operation, on the first day an intake of 2,500 c.c., and an output of 900 c.c., on the second, an intake of 3,600 c.c. and an output of 2,400 c.c. (Fig. 3). The same disproportion may be seen in Figure 2. This extreme discrepancy does not last more than two or three days. Soon an adjustment takes place, sometimes even the reverse discrepancy existing for a short time (Fig. 2). Whatever may be the cause of this early difference, the fact seems to be very important: it shows that polydipsia may precede the polyuria and is not simply consecutive to it. 
Camus and Roussy do not mention this fact and their published curves do not show it. We have noticed that the dogs operated on by the buccal route did not drink the first day, which may explain their failure to observe this phenomenon. But these authors did remark various discrepancies between the intake and output later in the polyuria and employed the designation "trouble with the regulation of water" and they insist on the fact that the polydipsia, which they think nevertheless to be consecutive to the polyuria, is enormous, inordinate and seems at times to be out of proportion to the needs of the organism.

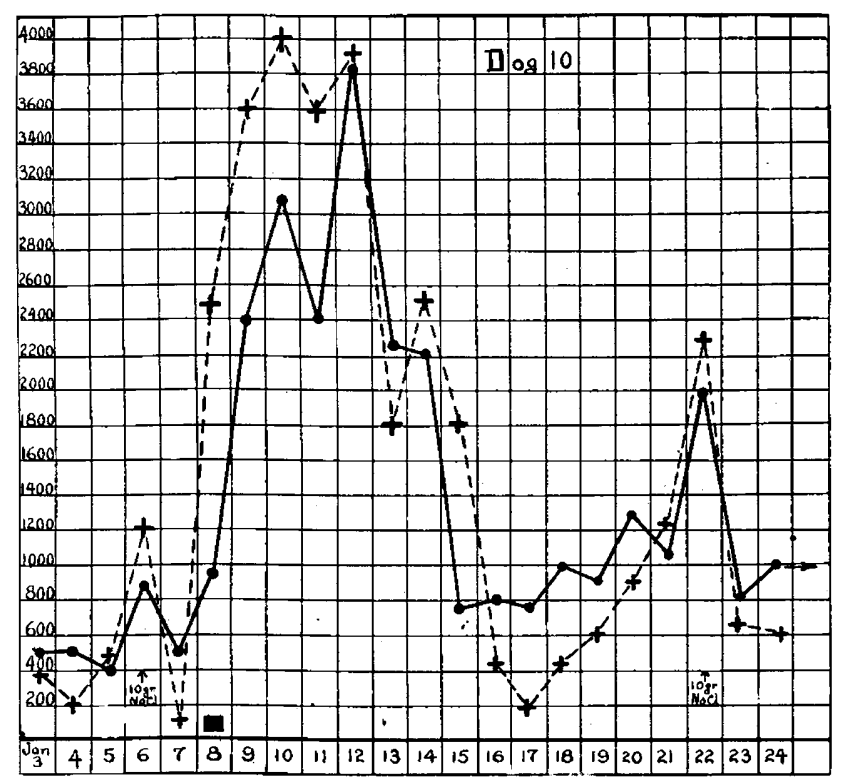

Fig. 3. +...+Intake; - Output; $\square$ Operation.

On the other hand, it is well known that the polyuria may appear (e. g. in comatose animals) and persist without any intake of water. We shall discuss later the significance of these facts.

In all but three dogs the polyuria lasted only from six to ten days and attained its maximum of from 1,000 to 3,000 c.c. on the third or fourth day as in the experience of Cushing ${ }^{24}$ and of Camus and Roussy.

In the ten dogs with a polyuria in which a clean-cut lesion was found it was always located in the hypothalamus just back of the stalk of the pituitary, except in Dog 14 where it was just in front. Of the remaining two, one (No. 13) had an extensive lesion of the tuber and the other (No. 18) a hemorrhage into the third ventricle

24. Cushing: Boston M. \& S. J. 168:901, 1913. 
with considerable trauma to hypothalamus and midbrain. It should be remembered that in the three dogs who were punctured but had no polyuria, no lesion of the hypothalamus was found but various lesions all around this region (including in Dog 21 the pituitary). Thus both the positive and negative results point to the same conclusion, namely, that the polyuria depends on a very small area just above the stalk of the pituitary known usually as the tuber cinereum.

4. Permanent Polyuria.-In three dogs the polyuria was permanent and had, as we shall see, all the characteristics of diabetes insipidus in man. These dogs presented other interesting symptoms: No. 3

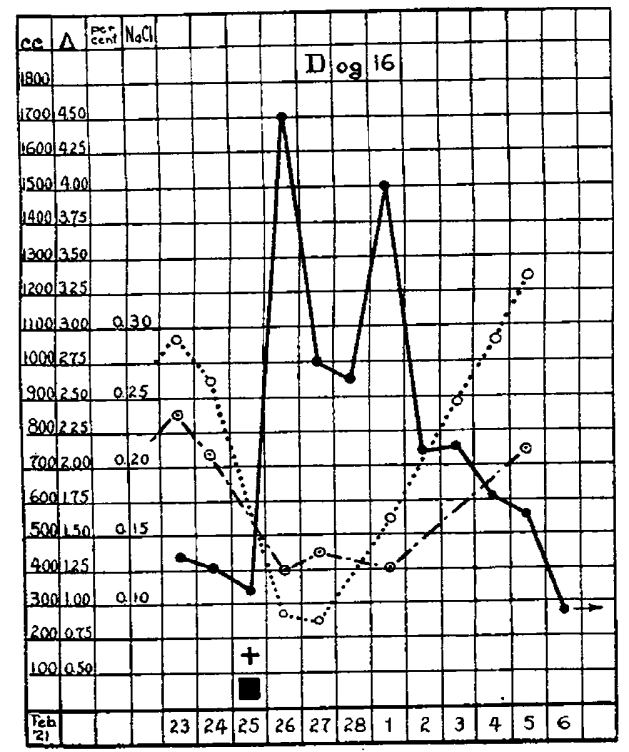

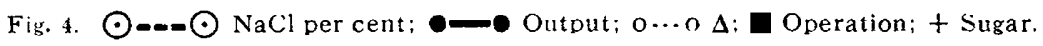

having progressive cachexia, hypothermia, and convulsions; Nos. 10 and 22 had typical adiposogenital syndrome. Such an association of symptoms is not a coincidence but is well explained by the lesions because in these $\log _{s}$ the lesion in the tuber was a more important one, although macroscopically very small. Those dogs having a still more extensive lesion of the tuber died very quickly as will be seen later.

In these polyurias the fall of the $\Delta$, in other words, the total molecular concentration, was always more marked than the fall of the concentration of the chlorids (Table 1). The consequence was that the dogs during the days of excessive polyuria lost an appreciable quantity of chlorids, as much as $3 \mathrm{gm}$. in twenty-four hours. This 
dissociation between the concentration of urea and other nonthreshold substances, and the concentration of chlorids is a banal one, as Cushny points out being found in all polyurias. It is explained in the modern theory of urinary secretion by impairment of the reabsorption of chlorids due to increased speed of flow in the tubules. In animals like the rabbit where there are other reasons for supposing a less developed power of reabsorption, any polyuria is accompanied by a marked increase in the percentage of chlorids in the urine (Cushny). After the polyuria had ceased it could be shown in three dogs that there was still a trouble of the regulation of water by the excessive polyuria provoked by the ingestion of chlorids.

TABLE 1.--Dog 10

\begin{tabular}{|c|c|c|c|c|c|}
\hline Date & $\begin{array}{l}\text { Urine } \\
24 \text { Hours }\end{array}$ & $\Delta$ & $\begin{array}{c}\text { NaCl, } \\
\text { per Cent. }\end{array}$ & $\begin{array}{l}\text { Total } \\
\text { NaCl }\end{array}$ & \\
\hline $\begin{array}{l}1 / 3 / 21 \\
1 / 4 / 21 \\
1 / 5 / 21 \\
1 / 6 / 21 \\
1 / 7 / 21 \\
1 / 8 / 21 \\
1 / 9 / 21 \\
1 / 10 / 21 \\
1 / 11 / 21 \\
1 / 12 / 21 \\
1 / 13 / 21 \\
1 / 14 / 21 \\
1 / 15 / 21\end{array}$ & $\begin{array}{r}500 \\
580 \\
425 \\
900 \\
565 \\
940 \\
2,400 \\
3.040 \\
2,150 \\
3,800 \\
2,240 \\
2,180 \\
670\end{array}$ & $\begin{array}{l}-3.70 \\
-3.40 \\
-3.90 \\
-3.60 \\
-3.95 \\
-0.45 \\
-0.55 \\
-0.95 \\
-0.75 \\
-0.95 \\
-1.40 \\
\ldots . .60 \\
-3.60\end{array}$ & $\begin{array}{l}0.20 \\
0.18 \\
0.23 \\
0.92 \\
0.46 \\
0.18 \\
0.10 \\
0.11 \\
0.082 \\
0.052 \\
0.09 \\
0.057 \\
0.111\end{array}$ & $\begin{array}{l}1.00 \\
1.04 \\
1.035 \\
8.800 \\
2.56 \\
1.69 \\
2.40 \\
3.344 \\
1.76 \\
1.976 \\
2.016 \\
1.24 \\
0.737\end{array}$ & $\begin{array}{l}10 \mathrm{gr} . \mathrm{NaCl} \\
\text { Operation }\end{array}$ \\
\hline
\end{tabular}

Dog 10 after a week of extreme polyuria (as much as 3,800 c.c.) presented during four months, until sacrificed, a permanent and very regular polyuria. Dog 22 had also a permanent polyuria which we followed during more than a month. Previous to his puncture the daily output of $\operatorname{Dog} 10$ was 470 c.c. with a $\Delta$ oscillating closely around -3.7. After the puncture the output was from 900 to 1,400 c.c. of a very pale urine and an average $\Delta$ of -2.2 Never was the previous $\Delta$ reached spontaneously. The constancy of this new concentration was such that the animal seemed to have adopted a new osmotic regulation and was in marked contrast to that observed in two nephritic dogs with polyuria which we had opportunity to observe. This constancy was very favorable for a systematic study, our aim being to verify that this polyuria had the characteristics of clinical diabetes insipidus. The same constancy was also present in Dog 22.

(a) Influence of Deprication of Food.-No appreciable influence was observed.

(b) Influence of Deprization of Water.-Dog 10 was restricted to 200 c.c. of water daily for two or three days. The output diminished only after the second day and then but slightly. The $\Delta$ reached 
the neighborhood of -3 . In one experiment there was an output of 1,000 c.c. on the third day of thirst, and the animal had lost at least 2,000 c.c. water. The blood, which was examined for us by Dr. Hilding Berglund before and at the end of the experiment, showed no evidence of concentration or retention.

(c) Effect of Pituitary Extract.-The effect of subcutaneous injection of pituitary extract was very interesting because Camus and Roussy state that it has no effect on the permanent polyuria which they produced in their dogs. The variations which they observed in the output after pituitary extract injections were of the same order

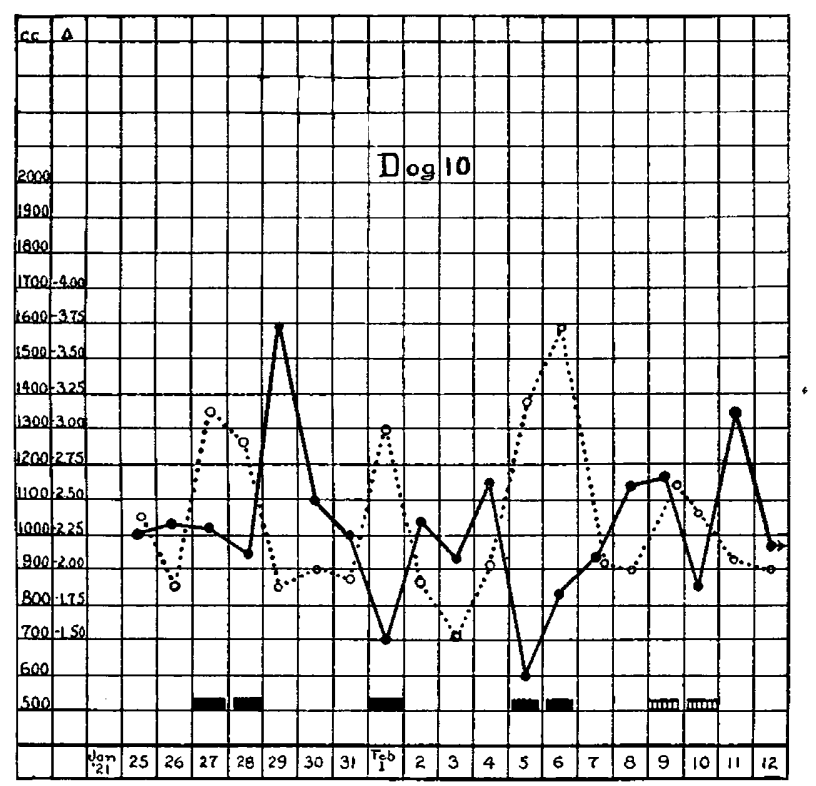

Fig. 5. Showing the action of Pituitary Extract and of reduction of the intake.

- Output; $0 \cdots \Delta_{i} 2 \mathrm{cc}$. Pituilary Extract in four injections reduced to $200 \mathrm{cc}$.

as the daily variations. The failure to discover such an effect was probably due to the fact that they did not employ repeated small doses nor observe the $\Delta$ or specific gravity.

The effect of subcutaneous injection of pituitary extract (Parke, Davis \& Co. pituitrin, and Lederle) was constant and definite, but much more apparent in the $\Delta$ than in the output (Fig. 5, Dog 10); it was the same in Dog 22. But the action, if we consider the dose employed and the necessity of repeated injections, is certainly less marked than in the average case of diabetes insipidus in man. Pituitrin had no definite action on the polyuria of two nephritic dogs. 
(d) Ingestion of Sodium Chlorid.-The addition of an excess of sodium chlorid to the diet always produced a considerable increase of the polyuria. Normal dogs, living on a diet poor in chlorids, when given $10 \mathrm{gm}$. sodium chlorid with their meat consume it with avidity, have only a slight polyuria or none at all, and eliminate the first day from 6 to $8 \mathrm{gm}$. of the salt to a concentration of from 0.9 to $1 \mathrm{gm}$. per cent. This seems to be the maximal ability of the normal kidney to concentrate sodium chlorid as we have seen it in giving from 20 to $30 \mathrm{gm}$. The excess of sodium chlorid is eliminated in two, three or even four days.

Table 1 shows the effect of ingesting $10 \mathrm{gm}$. of sodium chlorid on Dog 10 before the puncture polyuria. Quite different was the result on the fourteenth day of polyuria (Table 2), when the output rose from 1,050 to 1,970 c.c. The concentration reached only 0.6 , but $12 \mathrm{gm}$. chlorid were eliminated the first day and the elimination ceased

TABLE 2.-Dog 10

\begin{tabular}{|c|c|c|c|c|c|}
\hline Dute & $\begin{array}{l}\text { Urine } \\
24 \text { Hours }\end{array}$ & $\triangle$ & $\begin{array}{l}\mathrm{NaCl}, \\
\text { per Cent. }\end{array}$ & $\begin{array}{l}\text { Total } \\
\mathrm{NaCl}\end{array}$ & \\
\hline $\begin{array}{l}1 / 20 / 21 \\
1 / 21 / 21 \\
1 / 22 / 21 \\
1 / 23 / 21 \\
1 / 24 / 21 \\
1 / 25 / 21\end{array}$ & $\begin{array}{r}1,300 \\
1,050 \\
1,970 \\
780 \\
700 \\
1,000\end{array}$ & $\begin{array}{l}-2.35 \\
-2.10 \\
-1.4 \\
-2.50 \\
-2.60 \\
-2.4\end{array}$ & $\begin{array}{l}0.13 \\
0.155 \\
0.60 \\
0.25 \\
0.15 \\
0.12\end{array}$ & $\begin{array}{r}1.69 \\
1.62 \\
12.02 \\
1.95 \\
1.05 \\
1.20\end{array}$ & $10 \mathrm{gr}, \mathrm{NaCl}$ \\
\hline
\end{tabular}

the same day. This fact seems to us very interesting in view of the long prevailing doctrine that the polyuria of diabetes insipidus is a compensatory one due to the inability of the kidney to concentrate and the necessity for it to eliminate more water in order to perform its function of excretion (E. Meyer ${ }^{25}$ and others). It is difficult to conceive that a reaction against a supposed defect could have a better final result than the normal kidney is able to attain. We have found curves showing the same acceleration of the excretion of sodium chlorid in diabetes insipidus of man in the papers of $E$. Meyer and of Kennaway and Mottram ${ }^{26}$ given by these authors to show the inability of the kidney to concentrate!

The test was repeated twice on Dog 10 with the same result, namely the rapid elimination of the entire amount at a low concentration (from 0.33 to 0.45 ) with a marked increase of the polyuria. But it was possible to prove that the kidneys were perfectly able to concentrate normally the sodium chlorid by giving the salt on the second day of an experiment of thirst. Then the normal maximal

25. Meyer: Deutsch. Arch. f. klin. Med. 83:1, 1905; Deutsch. Klin. 13:282, 1911.

26. Kennaway and Mottram: Quart. J. Med. 12:225, 1918-1919. 
concentration of $1 \mathrm{gm}$. per cent. was reached and a $\Delta$ higher than before the operation (Table 3 ). A similar result was obtained where salt was given and pituitary extract injections with free water intake. The results with Dog 22 were entirely similar.

The polyuric action of chlorids is characteristic of diabetes insipidus (Oehme ${ }^{27}$ ). Our nephritic dogs did not show it. Therefore, it is interesting that we found the same excessive polyuria and quicker elimination of sodium chlorid not only during the polyuria but, by employing larger doses, after an apparent return to normal in dogs having a transitory polyuria. Dogs 5 and 6 a week after the cessation of their polyuria were given together with two normal dogs $30 \mathrm{gm}$. sodium chlorid. They had the first day a polyuria of 1,900 c.c., whereas the normal dogs passed only 1,000 and 1,200 c.c., and the elimination of the salt was much quicker. Dog 5 already after

TABLE 3.-Dog 10

\begin{tabular}{|c|c|c|c|c|c|c|c|}
\hline Date & $\begin{array}{c}\text { Urine } \\
24 \text { Hours }\end{array}$ & $\Delta$ & $\underset{\text { per Cent. }}{\mathrm{NaCl}}$ & & $\begin{array}{l}\text { Total } \\
\text { NaCI }\end{array}$ & $!$ & \\
\hline $\begin{array}{l}2 / 14 / 21 \\
2 / 15 / 21 \\
2 / 16 / 21 \\
2 / 17 / 21 \\
2 / 18 / 21 \\
2 / 19 / 21 \\
2 / 20 / 21 \\
2 / 21 / 21 \\
2 / 22 / 21 \\
2 / 23 / 21\end{array}$ & $\begin{array}{r}850 \\
950 \\
1,580 \\
1,000 \\
925 \\
565 \\
750 \\
1,300 \\
1,000 \\
1,020\end{array}$ & $\begin{array}{l}-2.1 \\
-2.3 \\
-1.90 \\
-2.4 \\
-2.5 \\
-2.9 \\
-4.05 \\
-2.15 \\
-2.4 \\
-2.25\end{array}$ & $\begin{array}{l}0.130 \\
0.130 \\
0.45 \\
0.224 \\
0.215 \\
0.200 \\
1.097 \\
0.205 \\
0.198 \\
0.119\end{array}$ & & $\begin{array}{l}1.105 \\
1.235 \\
7.110 \\
2.240 \\
1.988 \\
1.130 \\
8.227 \\
2.665 \\
1.980 \\
1.213\end{array}$ & ! & $\begin{array}{l}10 \text { gr. } \mathrm{NaCl} \\
200 \text { c.c. } \mathrm{H}_{2} \mathrm{O} \\
200 \text { c.c. } \mathrm{H}_{2} \mathrm{O}, 10 \text { gr. } \mathrm{NaCl}\end{array}$ \\
\hline
\end{tabular}

the first day eliminated his normal chlorid. Other salts than chlorid, other crystalloids, and the purine derivatives have little or no effect on the polyuria of diabetes insipidus (Oehme). We have verified this statement in our dogs for theobromine.

(e) The Effect of Fever.-Fever was not provoked experimentally but Dog 10 had a slight attack lasting some days following an injection abscess. During this time the polyuria was greatly diminished and the concentration of the urine increased in spite of the fact that he did not eat his entire ration.

The results of all these tests justify the conclusion that the persistent polyuria provoked in this manner has all the characteristics of diabetes insipidus in man and is therefore a true experimental diabetes insipidus.

(f) Effect of Denervation of the Kidneys.-This was a procedure of great interest because, so far as we know, it has never been done either in clinical or experimental diabetes insipidus. The denervation

27. Oehme and Oehme: Deutsch. Arch. f. klin. Med. 127:261, 1918. 
was performed on Dog 10 on the ninety-eighth day of his diabetes by Dr. William Quinby whose experience with the procedure is well known. ${ }^{28}$ All the nerves accompanying the renal vessels on both sides were destroyed and the surfaces of the vessels as far as possible decorticated. At this period, the polyuria, although constant, averaged only 750 c.c. with a $\Delta$ of -2.3 as against 470 c.c. with a $\Delta$ of -3.7 before the puncture.

The denervation was immediately followed by the polytria which usually ensues. The maximal denervation polyuria observed by Dr. Quinby in his experiments on normal dogs was 1,000 c.c., an exceptional amount. Clearly $\operatorname{Dog} 10$, who passed regularly 1,300 c.c. during eight days following denervation had two superimposed polyurias, one due to diabetes insipidus and the other to vasomotor disturbance produced by the denervation.

When the vasomotor polyuria had subsided after the usual delay the puncture polyuria continued until the animal was sacrificed, with the same characteristics. The average output was 850 c.c.; the $\Delta$ and specific gravity remained low; the effects of pituitary extract and sodium chlorid ingestion were unaltered, and the kidney showed the same ability to concentrate under the influence of pituitrin or restriction of water. A phenolsulphonephthalein test was done May 8, more than 75 per cent. being excreted in two hours and ten minutes. In the experience of Dr. Quinby this number is normal for dogs.

In Dog 22 the kidneys were denervated on the seventeenth day of his polyuria but owing to operative infection the immediate effect could not be observed. The slight fever he had accounts probably for the reduction of his polyuria and the rise of the $\Delta$ of his urine, which did not reach the level prevailing before puncture. As soon as the fever disappeared, the polyuria reappeared with exactly the same characteristics as before-the same $\Delta$ of -2.0 as against -3.4 before the puncture and the same ability to concentrate under the influence of pituitrin and restriction of fluids.

In Dog 23 a puncture polyuria was produced after the kidneys had been denervated.

We come thus to the important conclusion that the experimental diabetes insipidus is not suppressed by denervation of the kidneys and that the vasomotor polyuria following denervation may be superimposed on the diabetic polyuria.

(4) Coma, Convulsions and Cachexia.-Dog 4 died on the second day in a state characterized by coma and convulsive seizures. Dog 3 after an apparent recovery in which he was dull but ate normally

28. Quinby: Am. J. Physiol. 42:592, 1916; J. Exper. M. 23:535, 1916. 
fell into a progressive cachexia with hypothermia and died in convulsions. It is true that Dog 4 had signs of infection in his left temporal region but this could not possibly be the cause of the immediate coma. No other finding could account for this clinical picture than the lesion of the hypothalamus just back of the pituitary stalk. In both the integrity of the pituitary was verified histologically beyond question.

Three other Dogs, 5, 23 and to a certain extent 10, in the days immediately following the operation showed the syndrome so well described by Cushing and called by him cachexia hypophyseopriva: head drooping, back arched and apathy. All these animals had polyuria, one glycosuria and one later developed the adiposogenital syndrome.

5. The Adiposogenital Syndrome.-In Dog 3 there was an acute testicular atrophy. The spermatozoa and spermatids were almost completely absent with degenerative changes in the other cells. It is probable that this dog would have developed the adiposogenital syndrome if he had lived.

The entire syndrome developed insidiously in Dog 10. After a slight apathy for a few days he seemed perfectly normal except for his polyuria. Then he began gradually to gain weight and grow apathetic and sleepy. He gained $8 \mathrm{~kg}$. in three months. His testes and penis atrophied and he showed a complete indifference in the presence of a bitch in heat. The glucose tolerance could not be tested because he invariably vomited the sugar but intramuscular injection of 4 c.c. of adrenalin did not provoke a glycosuria. His hair which had been very rough became smooth and thin. $\mathrm{He}$ was also irresponsive to painful stimuli.

Dog 22 also had a testicular atrophy and gained considerable weight, most of which he lost, however, because of an acute infection, before it was necessary to sacrifice him.

\section{DISCUSSION OF RESULTS}

Perhaps the facts we have observed will throw some light on the pathogeny, still so obscure, of diabetes insipidus. We confirm the findings of Aschner, Camus and Roussy, and Houssay in showing that the polyuria is not due to injury of the pituitary gland but may be provoked with certainty by a lesion even extremely minute in the parainfundibular region of the hypothalamus. In most cases after such a lesion the polyuria is a transitory phenomenon but may be a permanent one which has all the characteristics of the diabetes insipidus observed clinically. In such cases there are also disturbances of metabolism and sexuality.

Is it possible to correlate this polyuria with those much more transitory ones induced in acute experiments by punctures or electrical stimu- 
lation in various parts of the nervous system, e. g., the gyrus sigmoideus (Bechterew), the cerebellar vermis (Eckhard ${ }^{29}$ ), or the fourth ventricle (Eckhard, ${ }^{29}$ Finkelnburg, Jungmann and Meyer ${ }^{30}$ )? We doubt it very much. These polyurias are immediate, small and very transitory. They are probably vasomotor phenomena, for at least that induced by puncture in the floor of the fourth ventricle cannot be produced after section of the splanchnic nerves (Eckhard ${ }^{29}$ ). On the contrary, we have seen that denervation of the kidneys in dogs with experimental diabetes insipidus, not only does not check their puncture polyuria but superimposes another on it. If we exclude the old experiments of Kahler which have been contested (cauterization of the fourth ventricle with silver nitrate), there is no evidence that a permanent polyuria can be obtained by lesion in these places. We may suppose, therefore, that the polyuria provoked by puncture of the hypothalamus is unique.

The first question which arises in interpreting the results of any experimental lesion of the nervous system is: are the effects noted due to an excitation or a destruction? The short duration of most of these polyurias suggests the former possibility in our experiments. But there are all transitions between the temporary and permanent polyurias as is also the case with clinical diabetes insipidus. Furthermore, study of the lesions shows that the location of the lesion is the essential factor. When the lesion is on the border of the necessary center or is extremely minute the polyuria is transitory. It would seem that destruction of the proper cells is necessary to a permanent polyuria. Besides in these cases there were other symptoms (cachexia, adiposity, genital atrophy) which are difficult to explain by an excitation. Of course, so far as the polyuria is concerned, the destruction of a nerve center may suppress an inhibition and so act ultimately as an excitation.

The second question which arises is: are the effects produced by direct nervous activity or through the mediation of some organ? We have seen that most probably the kidney is not involved. But we must consider one hypothesis both because of its historical interest and because of the seduction it offers to the mind, namely, the hypothesis of the pituitary origin of diabetes insipidus.

From the posterior lobe of the pituitary gland may be extracted a substance which has the remarkable property of being able to reduce all polyurias and especially that of diabetes insipidus. Although pituitary extract has a transitory diuretic effect, which was the first known, its ultimate action is a long lasting oliguria particularly apparent when these is a polyuria. Here is more than necessary to offer explanation of diabetes insipidus and in fact it has been attributed both to excessive

29 Eckhard: Ztschr. f. Biol. 44: 1903.

30. Jungmann and Meyer: Arch. f. exper. Path. u. Pharmakol. 73:49, 1913. 
secretion of the diuretic pituitary extract by the posterior lobe (Schäfer) and to lack of the oliguric pituitary extract (most clinicans).

The first explanation can be rejected immediately because the diuretic effect of pituitary extract is transitory, and inconstant, being already absent on the second injection (tachyphylaxy). The second explanation requires more attention. Pituitary extract even when injected slowly has in the normal animal a definite inhibitory action on the diuresis. Oehme and Oehme, after careful study, concluded that it acts directly on the kidney cells (or perhaps on the ultimate ganglia) since its effect is not influenced by denervation of the kidneys and that it probably acts by storage in the cell and not by fall of concentration. The effect far outlasts the vasomotor one. Can it then be supposed that diabetes insipidus is due to a defect in the secretion of the posterior lobe caused by a lesion of its regulatory center in the hypothalamus? We think not. The posterior lobe may be completely removed without producing a polyuria, and the same polyuria may be produced after the hypophysis has been previously removed (Camus and Roussy ${ }^{18}$ ).

Pituitrin has never been proved to be discharged into the circulation. The anatomic evidence, moreover, is entirely against the supposition that the posterior lobe is a secretory organ. It is composed of a mass of glia cells and fibers with a very poor blood supply. That the middle lobe pours a secretion into the posterior lobe and through it into the third ventricle has been apparently disproven. The hyalin and colloid masses are merely degenerative products increasing with age. We have therefore no evidence that pituitrin is anything else than a pharmacologically very interesting extract. Oehme and Oehme, who came to the same conclusions, point further that pituitary extract inhibits the action of theocin and the effect of theocin is not increased in diabetes insipidus as it should be if a state of hypopituitarism existed.

We may add to the consideration that the action of pituitary extract is on the kidney, that there is evidence that diabetes insipidus is not due to any defect in the kidney, even functional (thirst may precede the polyuria). Besides, even clinically, pituitrin is not a specific remedy for diabetes insipidus. Cases have been reported in which the injection of pituitrin did not relieve the thirst and in which there was a marked retention of urea. We have recently had opportunity to observe two patients in one of whom pituitrin not only did not relieve the thirst but produced an extreme dilution of the blood (fall of the blood urea nitrogen from 12 to $6 \mathrm{mg}$. on the day following the injection of 2 c.c. pituitary extract in four doses) and in the other an extreme edema and increase of weight of $5 \mathrm{~kg}$. in twelve hours. The first case was a giant with a metabolism -15 (P.B.B.H., Surg. No. 14,377), the other a boy, aged 17, with polydactylism and other signs of degeneration (P.B.B.H., Surg. No. 14,508). 
What, then, is the essence of diabetes insipidus? A prolonged polyuria may theoretically be due to a primary polydipsia, a simultaneous polydipsia and polyuria, or a primary polyuria. The following causes may play a rôle: (a) polydipsia by "unjustified" thirst (psychic), (b) polydipsia by justified thirst as it can be produced experimentally as a consequence of a period of daily exaggerated intake (Veil, ${ }^{31} \mathrm{Keg}$ nier, ${ }^{32}$ ), (c) simultaneous polydipsia and polyuria as it can be produced by a perturbation of the chemical (diabetes mellitus) or physicochemical regulation of the body fluids, (d) polyuria due to a disturbance of some hormone regulation of the kidney, (e) polyuria due to permanent nervous or vasomotor disturbance of the kidney, (f) functional inability of the kidney to concentrate inducing a compensatory polyuria, ( $g$ ) polyuria due to anatomic lesion of the kidney. Naturally, such an enumeration is purely artificial. We have no proof that these different conditions may be realized. We may immediately exclude " $a$ " and " $g$ " from our dogs as they are also from the definition of diabetes insipidus. Practically the discussion in later years has been concentrated on two explanations: one which considered the polyuria as a compensatory one due to the inability of the kidney (anatomically normal) to concentrate and the other which considered it an obligatory polyuria due either to a renal or to an extrarenal factor.

The teleological hypothesis of the inability of the kidney to concentrate has been vigorously criticized (Veil ${ }^{31}$ ). In. 1914 Aubertin and Ambard ${ }^{33}$ showed that the kidney in diabetes insipidus concentrates. But, nevertheless, recent authors such as Leschke, ${ }^{2}$ although recognizing the value of the criticism, point out that it is impossible in diabetes insipidus to make the kidney reach a normal concentraton. The argument often given that in experiments of thirst there may be a concentration of the blood proves simply that the water of the tissues had not the time to replace the water lost. It is the same concentration which may occur in severe diarrhea or sweating with the normal kidney.

We come, then, to a consideration of the possibility of an obligatory polyuria due either to renal or extrarenal factor. We bring evidence that experimental diabetes insipidus is independent of the nervous (if there be such) and vasomotor regulation of the kidneys. It persists after denervation and the denervation produces its usual effects. There is a summation of the two polyurias which shows well their independence. Although the significance of this fact is not yet clear it must be remembered also that it was possible to produce a marked puncture polyuria in a nephritic dog.

31. Veil: Deutsch. Arch. f. klin. Med. 119:376, 1916; Biochem. Ztschr. 91: 1918: Veil and Spiro: München. med. Wchnschr., 1918, p. 1119.

32. Regnier: Ztschr. f. exper. path. u. Therap. 18:139, 1916.

33. Aubertin and Ambard: Bull. et mém. Soc. méd. d. hôp. de Paris, 1914. 
These negative facts lead us to the consideration of an external factor. We bring now the positive fact that the polyuria can be preceded by the thirst. It is not necessarily preceded by it. The polyuria may appear and persist without any intake of water. But at any rate the polydipsia is not consecutive to the polyuria. The only possible way to reconcile these facts is to suppose that the nervous lesion produces at once thirst and polyuria. Such a combination could only arise by a disturbance of the physico-chemical equilibrium of the organism. This hypothesis has already been defended by Veil.

Veil attributes diabetes insipidus to the inability of the tissues to hold water and he tries to give to his hypothesis a chemical basis. But the abnormalities he observed in the chemical constitution of the blood in diabetes insipidus must always be susceptible of a double interpretation: it is very difficult to decide what is cause and what is effect of the excessive loss of water. In recent works, Berglund, ${ }^{34}$ and Bauer and Aschner ${ }^{35}$ contested the conclusions of Veil and showed that all the differences observed in the blood between normal individuals and cases of diabetes insipidus (e. g., after injection or ingestion of sodium chlorid) could be simply explained by the excessive loss of water in the latter. They found no evidence of a change in the permeability of the vessels for salt. But the failure of the chemical proof of an extrarenal factor is not surprising if we remember that the sensitiveness of the kidney to changes in the blood far surpasses the most accurate biochemical methods (Haldane and Priestly). This is proved by the well known fact that no modification can be found in the blood after intake of water, but there is an immediate diuresis.

It is actually proven that thirst is dependent not on the state of the blood but of the tissues. Cannon ${ }^{36}$ has suggested that the dehydration of the tissues causes arrest of the salivary secretion and the dryness of the throat consequently stimulates the nerve endings producing thirst. Therefore, it is interesting but probably unimportant to note also that the center which we traumatize to produce diabetes insipidus in dogs is an important gustatory center (Herrick ${ }^{15}$ ).

\section{SUMMARY}

The intimate mechanism of diabetes insipidus is unknown. It is provoked with certainty by a lesion of the postinfundibular region of the hypothalamus. There is evidence that such a lesion produces both polydipsia and polyuria, and the polydipsia may precede. Experimental diabetes insipidus persists after denervation of the kidney and cannot, therefore, be attributed to a disturbance of its nervous or vasomotor

34. Berglund: Studier över Koksaltomsättningens, Stockholm, 1920.

35. Bauer and Aschner: Wien. Arch. f. inn. Med. 1: 1920.

36. Cannon, W.: Croonian Lecture, Proc. Roy. Soc. Lond. 90B:283, 1918. 
regulation. We have no evidence of any hormone regulating the kidney, especially a pituitary hormone. The kidney conserves its ability to concentrate. All these facts point to an extrarenal factor as the essence of diabetes insipidus and it is certainly not a coincidence that this condition is accompanied both in clinical and experimental cases by other metabolic disturbances.

\section{PATHOGENY OF ADIPOSOGENITAL DYSTROPHY}

We have given proof that it is possible to provoke the cachexia "hypopyseopriva" and the adiposogenital syndrome (together with a permanent diabetes insipidus) by puncture of the postinfundibular region of the hypothalamus without touching the pituitary. The integrity of the gland and of its vascular connections was verified histologically beyond question. The possibility of this has been before asserted (Aschner, ${ }^{7}$ Camus and Roussy ${ }^{17,}{ }^{18,20}$ ) with strong arguments in support, but positive proof was never given because of the technic employed. Besides, Aschner who in 1912 claimed that acute genital atrophy without "Fettsucht" was due to extensive lesion of the tuber cinereum seems to have abandoned the idea in $1916^{13}$ and attributed all the metabolic disturbances to lesion of the anterior lobe of the pituitary. We show that not the extent but the location of the lesion is all important. The lesion can be so small as to be invisible to the naked eye.

The question immediately arises: Cannot these symptoms nevertheless be due to the pituitary by a disturbance of its innervation? The same question was discussed in relation to diabetes insipidus. We believe that it must be answered negatively here also. It must not be forgotten that the only nerve fibers known to go to the pituitary come from the superior cervical ganglia (Dandy, ${ }^{37}$ and Berkeley ${ }^{38}$ ) and removal of these ganglia does not lead to any of these symptoms. Furthermore, pituitary symptomatology has been built up by direct experiments on the gland where minute lesions of the hypothalamus, even contusions which later would not be discoverable with the microscope in hematoxylon and eosin sections were not and could not be taken into account. The situation of these nervous centers immediately adjacent to the pituitary is such that any manipulation of the gland suffices to injure them, as is seen by the occurrence of polyuria (Crowe, Cushing and Homans ${ }^{21}$ ). Therefore, it is not surprising that even the most careful extirpations of the pituitary (Crowe, Cushing and Homans) produce either quick death or cachexia or adiposity and genital atrophy. It is a strange fact that Aschner, who was the first to recognize the importance of the tuber cinereum, did not try by control experiments to determine with certainty what symptoms following

37. Dandy: Am. J. Anat. 15:333, 1913.

38. Berkley: Brain 17:515, 1894. 
removal of the pituitary were due to lesion of nervous centers. In his experiments on puppies Aschner obtained in successful cases adiposogenital dwarfism. Of course he gave as arguments against a nervous lesion in these cases the absence of glycosuria and polyuria. But we know that although a hyperglycemia is probably constant, glycosuria is much less frequent after puncture in this region than polyuria. And Camus and Roussy say that polyuria is much more difficult to obtain in young animals.

Besides Aschner does not give any details concerning the immediate symptoms following operation. He had a large immediate mortality from lesion of the tuber cinereum as he himself admits (four out of six animals). In almost every macroscopic verification the infundibulum was adherent to the base of the skull and in the only microscopic verification given of one adiposogenital dwarf there was evident nerve fiber degeneration and round cell infiltration in the tuber. It is surprising that Aschner, attributing the immediate fatal symptoms and acute genital atrophy in adults to lesion of the tuber, should attribute the adipososgenital dwarfism of the few surviving animals to removal of the pituitary.

If we except naturally the arrest of growth, the syndrome observed in young animals after extensive lesion of the pituitary is identical with that seen in adults (genital atrophy, adiposity, tolerance for sugar, absence of adrenalin effect). It would be incredible that such identical syndromes should be due in the young to lesion of the pituitary and in adults to a nervous lesion. Experimental lesions in the hypothalamus of puppies are therefore highly desirable.

Quite recently Lereboullet, Mouzon and Cathala ${ }^{39}$ have published a case of adiposogenital dwarfism with a suprasellar tumor and integrity of the pituitary, histologically established. The recent experiments of Smith ${ }^{40}$ and others who succeeded in causing stunting of growth in young tadpoles by removal of the pars buccalis of the hypophysis seem conclusive until one remembers the resultant maldevelopment of the adjacent nervous tissue. It is apparently not with impunity that the normal biostactic relations of the brain may be disturbed in the developing embryo.

What, then, is the function of the pituitary? It is impossible to admit that an organ with such a highly differentiated glandular structure as the pars buccalis should not have a function at some period of life or at least at some period in the development of the vertebrate phylum. But we must admit that we have little actual knowledge of its functional significance in the adult mammal. The numerous cases published of destruction of the pituitary without symptoms point

39. Lereboullet, Mouzon and Cathala: Rev. neurol. 28:154, 1921.

40. Smith: Wistar Inst., Pub. No. 11, 1920. 
in this direction. The progressive dwindling of the pars infundibularis with cystic degeneration until in man it is hardly discoverable by aid of the microscope points in the same direction.

Have we any evidence of a hyperfunction of the pituitary? The question of acromegaly and giantism is still unresolved. The frequency of hypertrophy or adenoma of the pituitary, as Marie was the first to point out, seems to point to a functional disturbance of the gland. But how many puzzling contradictions exist (acromegaly without any demonstrable pituitary lesion [Yamada ${ }^{41}$ ] etc.). It should be remembered that feeding experiments have failed to reproduce the syndrome (see however the recent work of Uhlenhuth ${ }^{42}$ in salamanders). These feeding experiments may have great intercst for the physiology of nutrition but it is dangerous to draw from them conclusions concerning the function of endocrine organs. Besides, tissue hypertrophies may be produced by a purely nervous lesion (cheiromegaly in syringomyelia). Therefore, it is not impossible that the acromegalic syndrome may be due to an effect of the pituitary growth on the hypothalamic centers. It is very suggestive in this regard that tumors of the pineal region produce metabolic and sexual disturbances of a hypertrophic nature. The fact that these troubles must be due to pressure on neighborhood centers is well shown by the constant occurrence in the syndrome of symptoms due to various lesions of the brain and cranial nerves and in some cases by the development of the peculiar symptoms such as genital hyperplasia and adiposity in the final stages of the disease (Marburg).

As to the function of the posterior lobe the experimental evidence is unequivocal. Its removal causes no symptoms. Moreover, its structure is nonglandular. Camus and Roussy are quite justified in speaking of it as an atrophied nervous lobe. But we must reckon with the fact that from it may be extracted a very active substance, pituitrin (the origin of pituitrin in the posterior lobe and not in the pars infundibularis we accept as an established fact). It is difficult to conceive that such a substance, which is found in the pars nervosa of all vertebrates, should be without significance. Since the pars nervosa is composed almost wholly of glia, it is quite possible that this material may be extracted from the glia anywhere.

We have, on the other hand, a body of facts which show that in the hypothalamus are important nervous centers controlling manifold visceral regulations. Their anatomic connections are very imperfectly known. They are intimately connected with the olfactory and gusttatory (Herrick ${ }^{15}$ ) systems, specialized parts of the visceral nervous system. There is some anatomic evidence also that these centers have important connections with the general visceral system, for retrograde

41. Yamada: Mitt. a. d. Med. Fakult. d. K. Univ. zu Tokyo 18:411, 1917.

42. Uhlenhuth: J. Gen. Physiol. 3:347, 1921. 
changes occur in their nuclei after section of the sympathetic trunk in the neck (Huet ${ }^{36}$ ) and after destruction of the sympathetic nucleus of the vagus (Brugsch, Dresch and Lewy ${ }^{16}$ ).

The physiology of the hypothalamus is also beginning to be known although the experiments have usually been acute. After lesions experimentally produced have been noted disturbance of heat regulation, dilatation of the pupil, change in the pulse and respiratory rate, glycosuria, transitory polyuria, polypnoea, etc. We believe that we bring proof also that trauma of this region may cause in addition, depending on the site and size of the lesion, permanent polyuria, adiposogenital dystrophy, cachexia and even rapid death.

The mechanism of production of the adiposity and genital regression is completely obscure. The two symptoms are in some form constantly associated, which justifies the term adiposogenital dystrophy. The fact that the adiposity is out of proportion to the adiposity of the castrate excludes the possibility of considering it as a simple consequence of the genital atrophy. Besides, the adiposity, as is well known, is only one element of a far-reaching metabolic disorder (apathy, low basal metabolism, high tolerance for sugar and epinephrin, arrest of growth in the young, etc.). Furthermore, we have seen that diabetes insipidus is probably also a metabolic disturbance.

Through what intermediary, nervous or endocrine, does the lesion of the hypothalamus produce such disorders? It is at present impossible to answer the question. It must be simply pointed out that (except naturally for the genitals) it is difficult to advocate a disturbance of any particular endocrine organ, including the hypophysis, these organs being histologically normal. The difficulty of explanation is especially acute for the genital atrophy. We have seen that the degeneration of the germinal cells may appear extremely early (Dog 3). Later (Dog 10) there is also a definite sclerosis of the interstitial gland which may account for the late regression of the secondary sex characters and the loss of libido.

Camus and Roussy, assuming that the hypothalamus controls the kidney by a nervous mechanism and pointing to the common embryologic origin of the kidney and sex glands, make the same supposition of a nervous control for the latter. But we came to the conclusion that the diabetes insipidus is not dependent on the nevous control of the kidney.

If such a nervous regulation of the sex glands exist, the nerve fibers on which it depends must leave the central nervous system very high because, so far as we know, in no case of complete transection of the spinal cord, either in man or animals, has an atrophy of the genitalia been observed. The recent work of Kuntz ${ }^{43}$ may

43. Kuntz: Anat. Rec. 17:203, 221, 1919. 
point to a nervous trophic regulation of the testes. The author showed that the removal of the inferior mesenteric ganglion in dogs produces a rapid degeneration of the germinal cells of the testes with an hypertrophy of the interstitial cells. The few animals operated on were killed after about three weeks and no details are given concerning their sexual capacity. The author himself attributes the degeneration observed to vasomtor disturbance. Further research along these lines is evidently desirable.

Provisionally we are more inclined to consider the genital atrophy in connection with the invariably accompanying metabolic disorders. The extreme sensitiveness of the germinative cells to toxic influences and to deficient diet (e. g. in vitamins, Allen ${ }^{44}$ ) is a well known fact, and may perhaps explain the regression of the gonads in the metabolic disorders under discussion. But we realize that such words as "metabolic" merely cover our ignorance and throw little light on the subject.

The establishing of these ideas would do much to clear away the many puzzling contradictions which continue to worry the clinicians; pituitary destruction without pituitary symptoms, pituitary symptoms with integrity of the pituitary, occurrence of diabetes insipidus and adiposogenital dystrophy in encephalitis lethargica whose nuclear election is well known, frequency of occurrence of polyglandular syndromes by lesion of the pituitary region, the paradox of regression of pituitary symptoms by roentgen-ray treatment of pituitary adenomas, treatment which must destroy what little is left of the glandular cells (Béclère ${ }^{45}$ ).

All these contradictions and many others may be explained by the presence in the brain stem just above the pituitary of an important head ganglion of the visceral nervous system. We believe that the time is not far distant when the neuropathologist will no more think of omitting to examine the hypothalamus than he would the motor cortex.

\section{CONCLUSIONS}

In order to distinguish among the symptoms which are commonly ascribed both in clinical cases and in experiments on animals to the lesion or removal of the hypophysis, those which may be due to lesion of the adjacent nervous centers, systematic punctures of the hypothalamus have been made in adult dogs. The lateral route of Paulesco and Cushing has been employed, which gives a perfect exposure of the region and permits avoidance of the hypophysis with practical certainty, contrary to the transsphenoidal procedure hitherto employed for the purpose. The results of the experiments may be summarized as follows :

1. The consequences of the puncture depend strictly on the localization of the lesion and, when the localization is correct, on the extent.

44. Allen: Anat. Rec. 16:93, 1918.

45. Béclère: Paris méd. 11:97, 1921. 
2. A lesion, even extremely minute, of the para-infundibular region of the hypothalamus provokes with certitude (in thirteen of thirteen dogs) a polyuria which appears in the first two days. According to the extent of the lesion it varies from a transient one lasting from six to eight days to an apparently permanent polyuria.

3. In the latter case other important symptoms were present, e. g., cachexia "hypophyseopriva," genital atrophy and adiposity.

4. The permanent polyuria has all the characteristics of diabetes insipidus in man, e. g., possibility of concentration when intake of fluids is restricted, when pituitary extract is injected subcutaneously or in the presence of fever, excessive polyuric action to the administration of chlorids, absence of theobromine effect.

5. The thirst may precede the polyuria. In five cases the increase in intake preceded the output by one day, and during several subsequent days there was a marked discrepancy between the intake and output. On the other hand, the polyuria may appear and persist without intake of water, e. $g$. in comatose animals.

6. The experimental diabetes insipidus does not depend on a disturbance of a supposed nervous or vascular regulation of the kidney. It may be induced in animals whose kidneys have previously been denervated and when present persists after denervation of the kidneys with the same characteristics.

7. Lesion of the tuber cinereum has produced in two dogs a cachexia "hypophyseopriva" with acute genital atrophy and in two other dogs an insidiousiy developing adiposogenital dystrophy. The integrity of the pituitary was in each case verified histologically. The same dogs had persistent polyuria.

8. An extensive lesion of the tuber cinereum is incompatible with life. The animals either die quickly or after a period of apathy in coma and convulsions.

9. Glycosuria was an inconstant result of the lesion and seemed to depend probably on the state of nutrition of the animal.

10. Lesion, even deep, of the base of the brain outside of the parainfundibular region may produce a glycosuria but never a polyuria, the operative trauma being the same as in the previously mentioned polyuric animals. The relationship of the mamillary bodies to the polyuria is undetermined. Involved in a few cases, they were uninjured in other animals which had nevertheless polyuria and other symptoms.

11. The situation of this important nervous center and the minuteness of the lesion necessary to provoke characteristic symptoms probably explains the results of operations on the hypophysis in both young and adult animals. There is no evidence at present that the lesion acts by the intermediation of the pituitary. 